Supplementary Information for

\title{
Reconfigurable 2D/0D p-n Graphene/HgTe Nanocrystal Heterostructure for Infrared Detection
}

Ulrich Nguétchuissi Noumbé1\&, Charlie Gréboval2\&, Clément Livache², Audrey Chu², Hicham Majjad¹, Luis E. Parra López¹, Louis Donald Notemgnou Mouafo', Bernard Doudin ${ }^{1}$, Stéphane Berciaud ${ }^{1,3}$, Julien Chaste ${ }^{4}$, Abdelkarim Ouerghi ${ }^{4}$, Emmanuel Lhuillier $^{2^{*}}$, Jean-Francois Dayen ${ }^{1,3 *}$

1 Université de Strasbourg, CNRS, Institut de Physique et Chimie des Matériaux de Strasbourg (IPCMS), UMR 7504, 23 rue du Loess, Strasbourg, 67034, France.

2Sorbonne Université, CNRS, Institut des NanoSciences de Paris, INSP, F-75005 Paris, France

3 Institut Universitaire de France, 1 rue Descartes, 75231 Paris cedex 05

${ }^{4}$ Centre de Nanosciences et de Nanotechnologies, CNRS, Université Paris-Saclay, C2N, Palaiseau 2110, France.

\& these two authors have equal contributions

To whom correspondence should be sent: el@insp.upmc.fr, dayen@unistra.fr

\section{Table of content}

1. Graphene characterization - Transport in graphene Hall bar ...........................................2

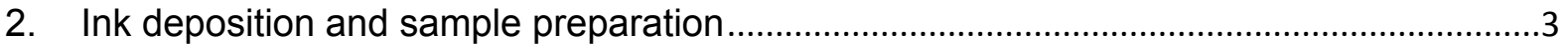

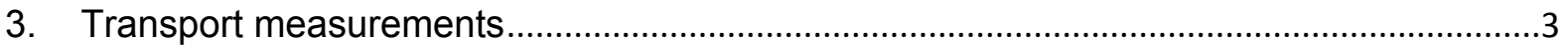

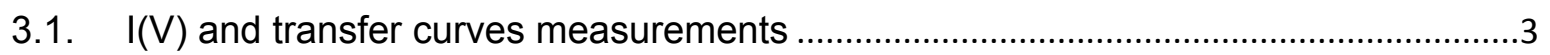

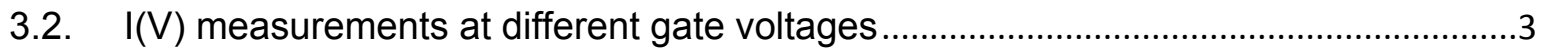

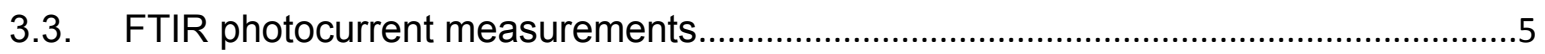

3.4. Photocurrent measurements with an electrically chopped laser at $1.55 \mu \mathrm{m}$.............6

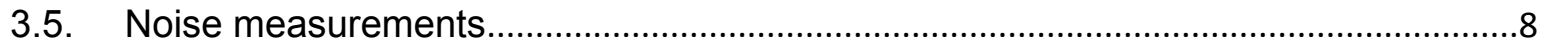

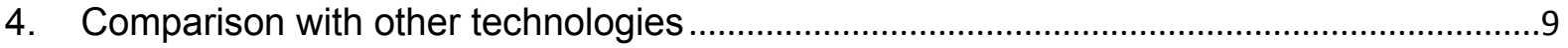

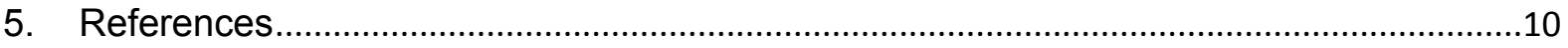




\section{Graphene characterization - Transport in graphene Hall bar}

Graphene Hall Bar with $300 \mu \mathrm{m}$ length and $50 \mu \mathrm{m}$ width has been designed using the same etching technique as for graphene interdigits on $\mathrm{LaF}_{3}$ substrate, and then contacted using a standard laser lithography. For the latter, a positive AZ 1505 resist is spin-coated and baked at $105^{\circ} \mathrm{C}$, following by UV Laser exposition of the target region. The resist is developed using a bath of AZ 726 for $20 \mathrm{~s}$ and rinsed in deionized water. Metal deposition Ti (10 nm)/Au (40 $\mathrm{nm}$ ) is then performed by electron beam evaporator in high vacuum chamber, followed by liftoff in acetone. A microscopy image of the hall bar is given in Figure S1. This geometry is used to probe transport in pristine graphene.

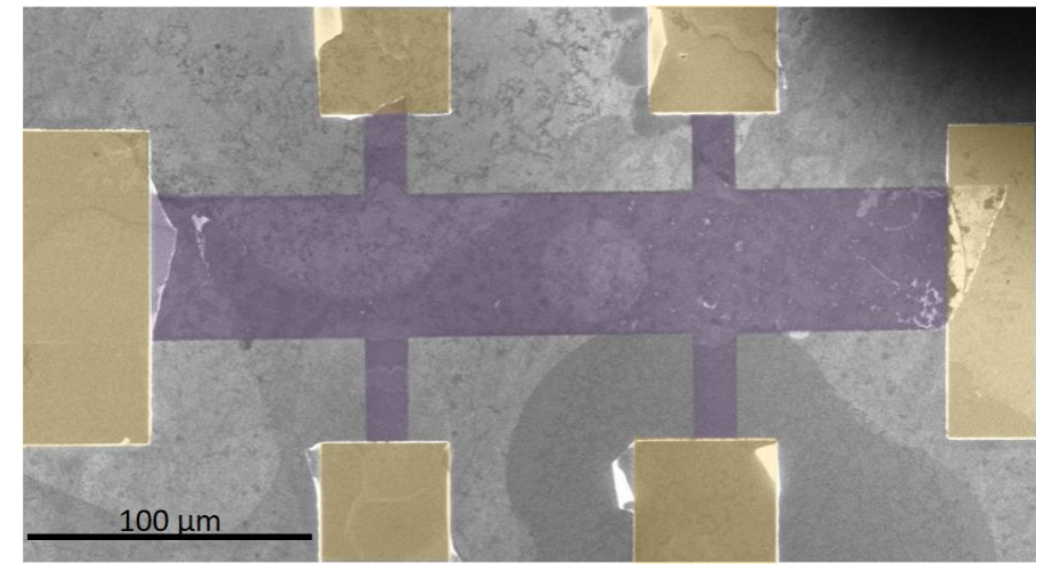

Figure S1 Image of the graphene Hall bar. 


\section{Ink deposition and sample preparation}

The $\mathrm{LaF}_{3}$ substrate patterned with interdigitated electrodes is cleaned with acetone, rinsed with isopropanol and dried under nitrogen flow. The HgTe $4 \mathrm{k}$ ink solution is then spin-coated on top of the electrodes at $1200 \mathrm{rpm}(400 \mathrm{rpm} / \mathrm{s})$ for $180 \mathrm{~s}$ and $3000 \mathrm{rpm}(1500 \mathrm{rpm} / \mathrm{s})$ for 60 $\mathrm{s}$. The sample is then dried under vacuum for $2 \mathrm{~h}$. Film thickness is then measured using a Dektak XT profilometer. Figure $\mathbf{S} 2$ shows a profile measured on the edge of the active area of the device.

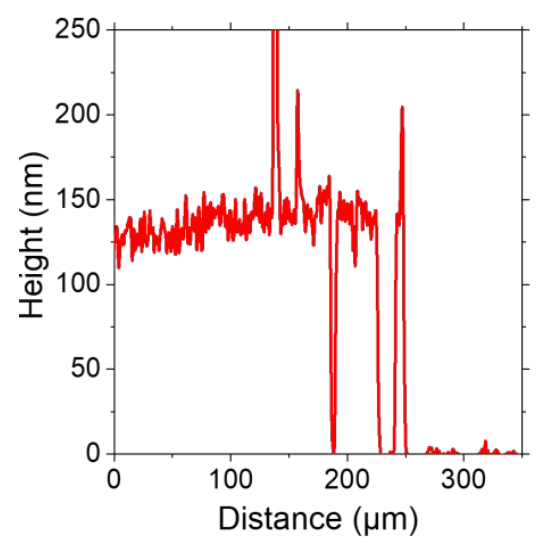

Figure S2 Profile of the HgTe film on the edge of the device. Profile has been measured using a Dektak XT profilometer with $1.5 \mathrm{mg}$ of force applied.

\section{Transport measurements}

\subsection{I(V) and transfer curves measurements}

Setup: The sample is placed in a cryostat and connected to the two channels of a Keithley 2634B. Channel A is used to apply a drain-source bias and measure the channel current. Channel $B$ is used to apply a gate bias and measure the leakage current.

\section{2. $\quad I(V)$ measurements at different gate voltages}

Figure S3 presents I(V) curves measured at different gate voltages under dark conditions. Far from $-2 \mathrm{~V}$ of gate voltage (Figure $\mathbf{S 3} \mathrm{a}$. and b.) the sample presents a linear and ohmic behavior. However, when it comes close to this value an asymmetrical behavior clearly appears (Figure S3 c. and d.). This is a consequence of the formation of a $p-n$ junction in the channel. 

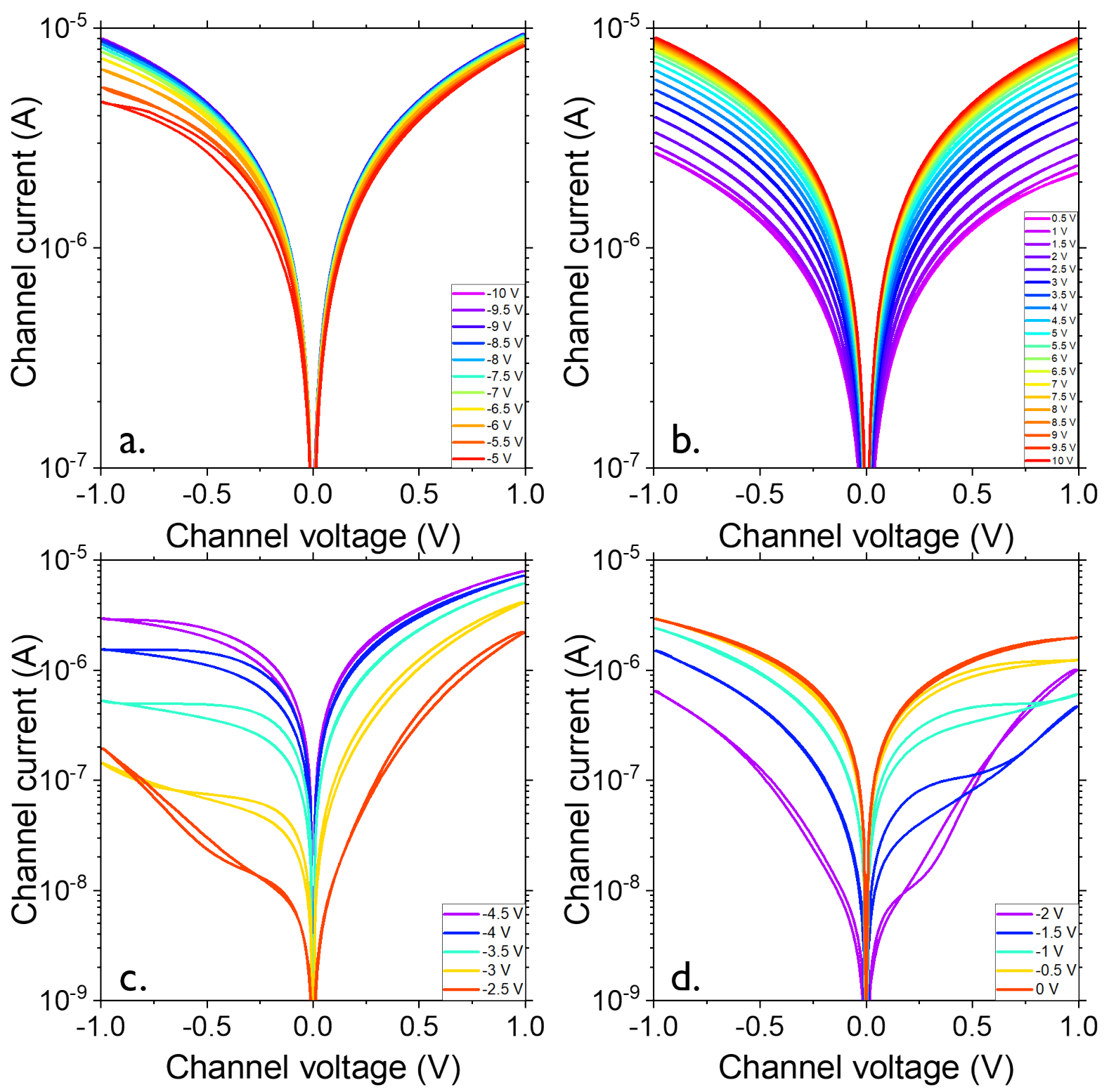

Figure S3 I(V) characteristics at different gate voltages illustrating the different regimes under dark conditions. a. and b. I(V) taken under high negative (resp. positive) gate voltage: ohmic behavior following the transfer curve. Measurements have been conducted at $220 \mathrm{~K}$. c. and d. I(V) characteristics at low negative gate voltages exhibiting asymmetric behavior as the result of the formation of the $p-n$ junction. Measurements have been conducted at $220 \mathrm{~K}$. 


\subsection{FTIR photocurrent measurements}

For FTIR photocurrent measurements we use a Fischer Nicolet iS50. The spectra are acquired with a resolution of $4 \mathrm{~cm}^{-1}$ and averaged over 32 scans. Figure $\mathbf{S} 4$ a. shows a scheme of the setup where the sample is biased with a Keithley 2634B, the current is amplified through a DLPCA-200 transimpedance amplifier (TIA) before being sent back to the FTIR electronics to perform the Fourier transform. As for the chopped laser photocurrent measurements we observe a huge drop of the response when we apply positive gate biases as shown in Figure $\mathbf{S} 4 \mathbf{b}$. Spectra have been normalized by the gain of the amplifier to be compared.

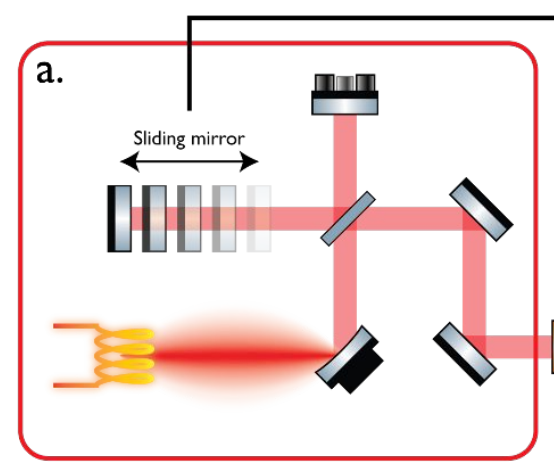

FTIR

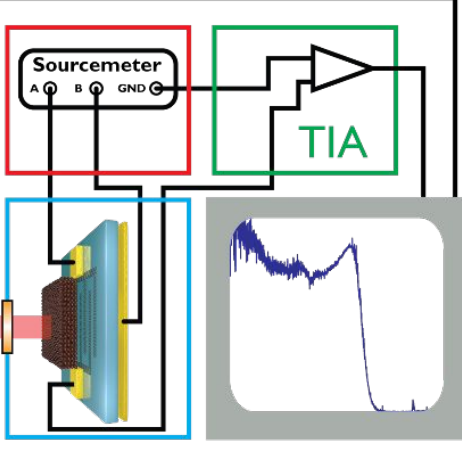

Cryostat

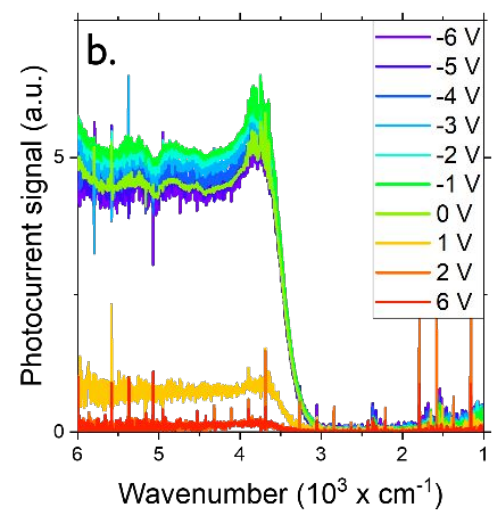

Figure S4 FTIR photocurrent spectra measurements. a. Scheme of the setup. Light coming from the FTIR is shone on the sample placed in a cryostat. The sample is biased using a Keithley 2634B and the current is amplified through a DLPCA-200 transimpedance amplifier (TIA). The signal is sent back to the FTIR to perform Fourier transform of the interferogram. $b$. Photocurrent spectra taken at different gate voltages from -6 to $6 \mathrm{~V}$ under $0.5 \mathrm{~V}$ drain-source bias at $220 \mathrm{~K}$. 


\subsection{Photocurrent measurements with an electrically chopped laser at $1.55 \mu \mathrm{m}$}

Figure S5 shows the experimental setup used to measure photocurrent under pulsed excitation with an electrically chopped laser diode at $1.55 \mu \mathrm{m}$. The sample is placed in a cryostat and cooled down to $220 \mathrm{~K}$. It is then biased using a Keithley $2634 \mathrm{~B}$ sourcemeter and current is amplified through a DLPCA-200 transimpedance amplifier (TIA). The output signal of the amplifier is then either sent to a Tektronik MDO3102 oscilloscope to get time resolved response or to an MFLI lock-in amplifier to extract the photocurrent at the chopping frequency. For time resolved measurements the setup limitation is mainly due to the bandwidth of the TIA which is $50 \mathrm{kHz}$ meaning that the temporal resolution is about $7 \mu \mathrm{s}$.

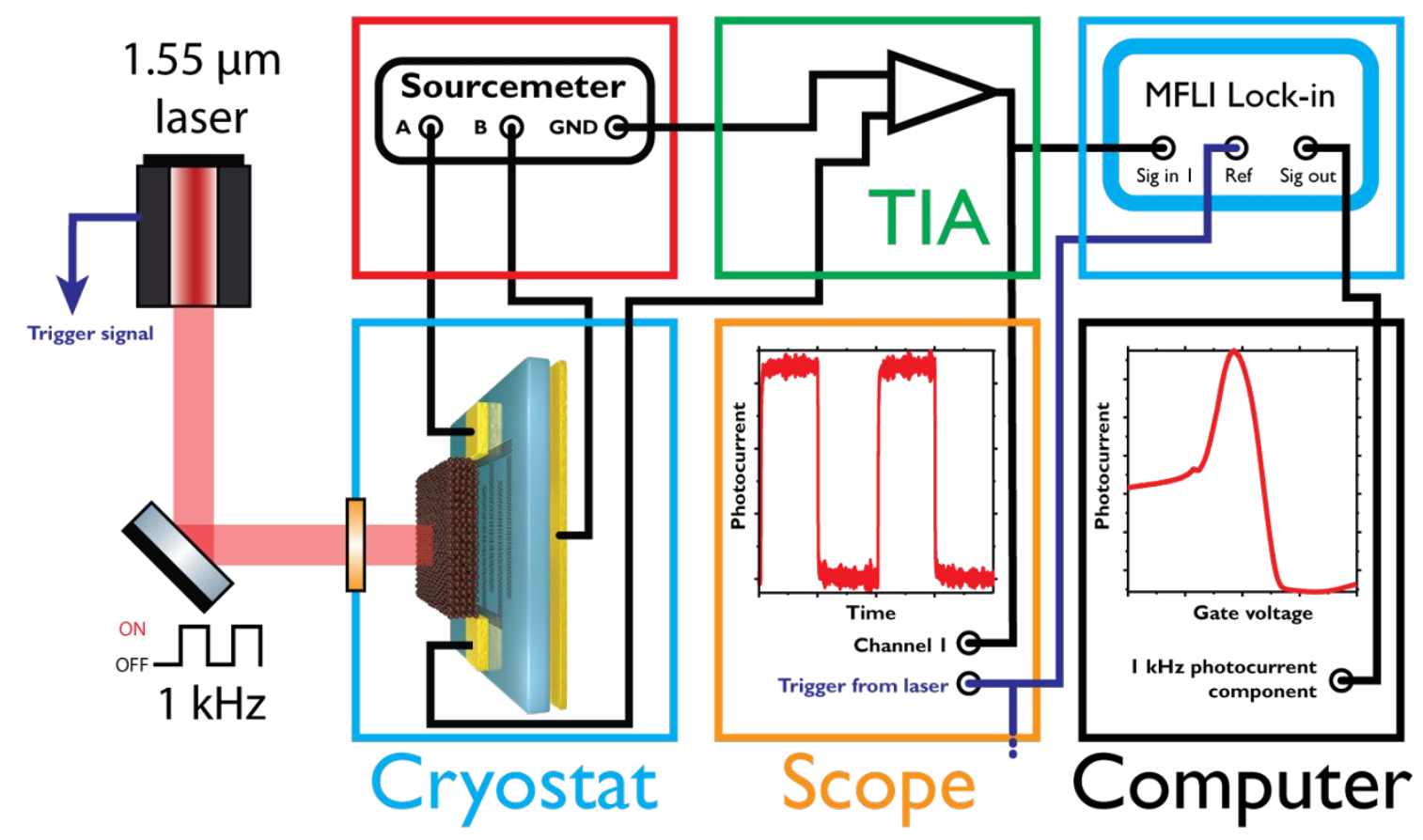

Figure S5 Chopped laser photocurrent measurements. Scheme of the setup that allow both time-resolved photocurrent measurements with an oscilloscope and the extraction of the 1 $\mathrm{kHz}$ component of the photocurrent during a gate voltage sweep through a lock-in amplifier. 
In Figure S 6, we have checked that the time response of the device remains fast for a broad range of incident power
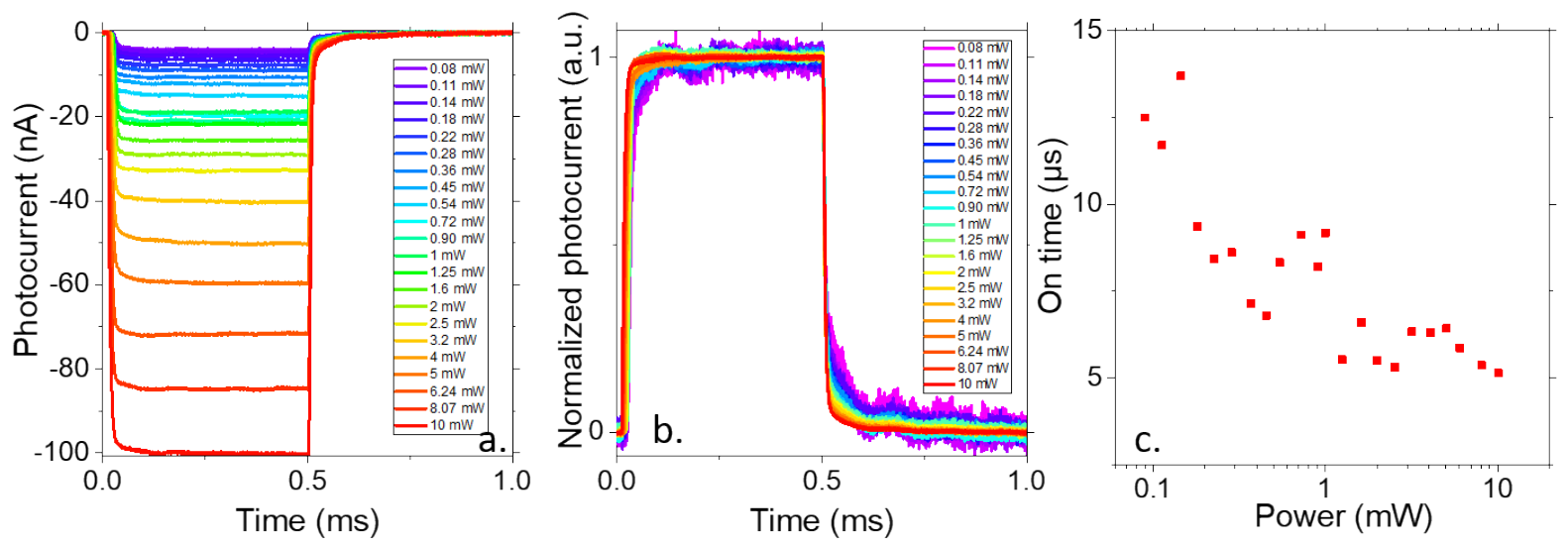

Figure $S 6$ Time response of the device for various incident power. Part a provides the nonnormalized data, while for part $b$ the data have been normalized. c. turn-on time as a function of the incident power.

In Figure S 7, we follow the power dependence of the photocurrent. A power law fit of the current plotted a s function of the power unveils a 0.7 exponent. This value is intermediate between the value of 1 expected for monomolecular process (trapping) and the value of half resulting from a bimolecular process (electron hole recombination), meaning that both processes are involved.

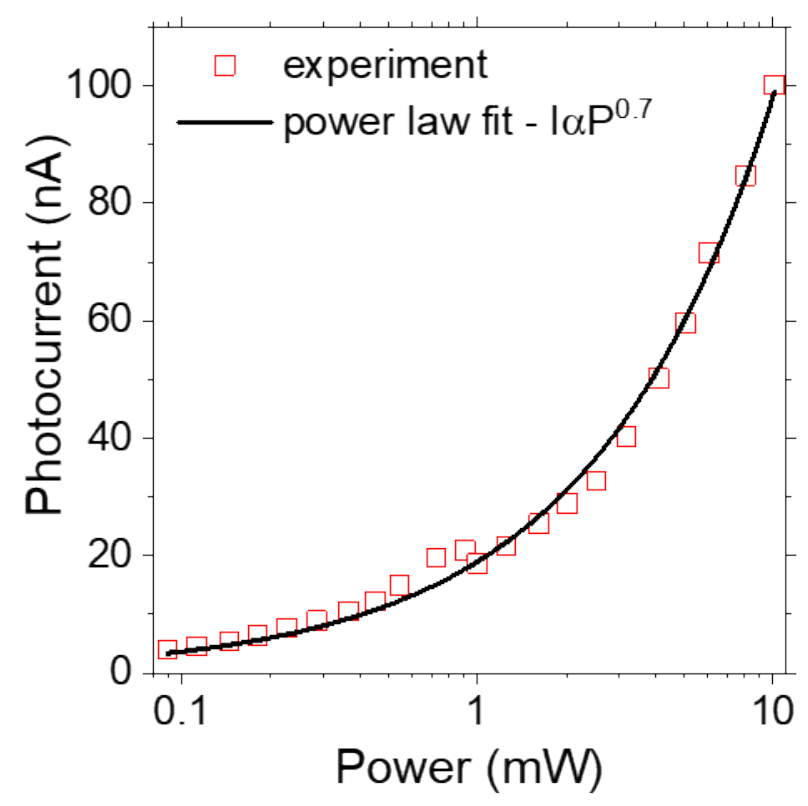

Figure S 7 photocurrent as a function of the incident power 


\subsection{Noise measurements}

To measure the current noise spectral density the setup of Figure $\mathbf{S 8}$ a. has been used. A Keithley 2634B is still used to apply the gate voltage but the drain-source voltage is now applied by the DLPCA-200 TIA. For all noise measurements the drain-source bias is $0.5 \mathrm{~V}$. The noise spectral density is acquired for different gate voltages from $10 \mathrm{~Hz}$ to $3 \mathrm{kHz}$ and averaged over 100 scans. The value recorded at $1 \mathrm{kHz}$ is further used to calculate the detectivity. We can notice that the current noise spectral density follows the trend of the transfer curve as shown on Figure S8 b.

a.

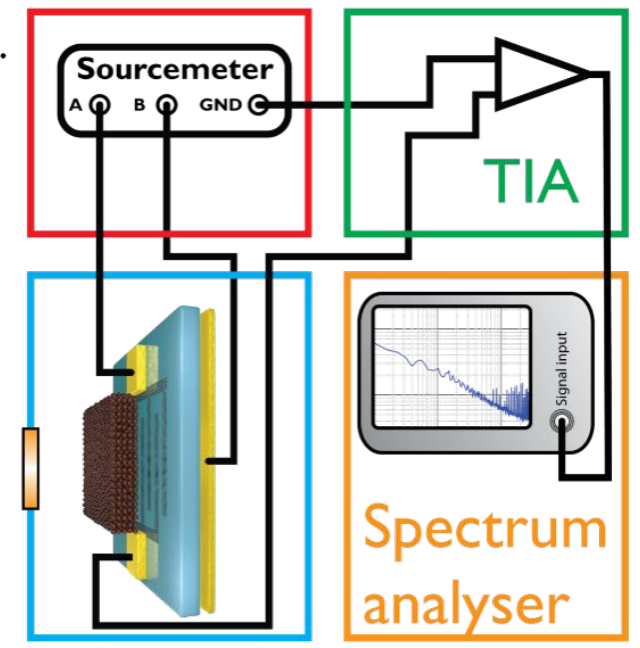

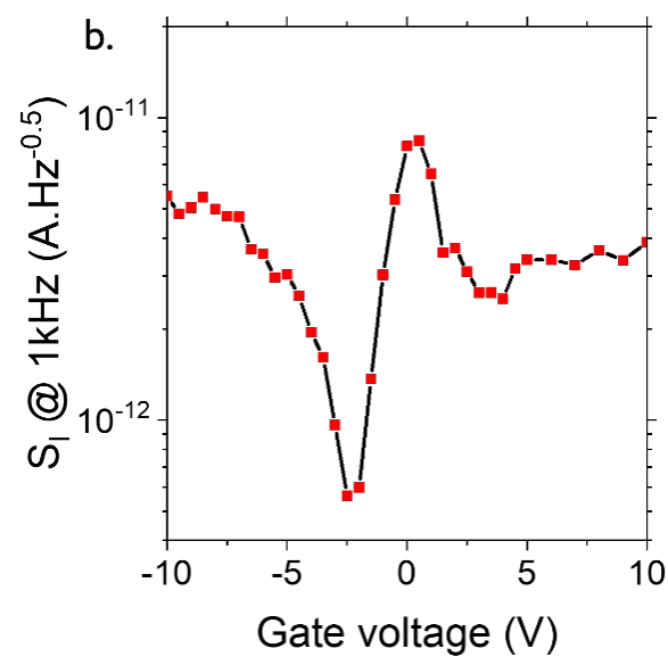

Figure S8 Noise measurement setup. a. A Keithley $2634 B$ is used to apply a gate voltage and the channel voltage is applied by the DLPCA-200 transimpedance amplifier (TIA). The amplified current is sent to a Stanford SR780 spectrum analyzer to measure current spectral noise density. b. Current noise spectral density at $1 \mathrm{kHz}$ and $220 \mathrm{~K}$ under $0.5 \mathrm{~V}$ bias at different gate voltages used to calculate detectivity. 


\section{Comparison with other technologies}

Table S 1 Performance for various infrared nanocrystal based photodetectors

\begin{tabular}{|c|c|c|c|c|c|c|c|c|c|}
\hline Technology & $\begin{array}{l}\text { Absorbin } \\
\mathbf{g} \\
\text { material }\end{array}$ & $\begin{array}{c}\text { Detection } \\
\text { wavelengt } \\
\mathrm{h} \\
(\mu \mathrm{m}) \\
\end{array}$ & $\begin{array}{l}\text { Operating } \\
\text { Temperatur } \\
\text { e (K) }\end{array}$ & $\begin{array}{l}I_{\text {dark }} \\
@ 1 \\
V_{D S} \\
\text { (A) }\end{array}$ & $\begin{array}{c}\text { Responsi } \\
\text { vity (A.W- } \\
\text { 1) }\end{array}$ & $\begin{array}{l}\text { Detectivit } \\
\text { y (jones) }\end{array}$ & $\begin{array}{c}\text { Time } \\
\text { respons } \\
\text { e } \\
(\mathbf{s}) \\
\end{array}$ & $\begin{array}{c}D^{*} / T_{\text {resp }} \\
\left(\text { Jones.s }{ }^{-1}\right)\end{array}$ & Comment \\
\hline $2 \mathrm{D}-0 \mathrm{D}$ hybrid ${ }^{1}$ & $\mathrm{PbS}$ & $\begin{array}{c}0.95- \\
1.45 \\
\end{array}$ & RT & $\begin{array}{c}710^{-} \\
5 \\
\end{array}$ & $510^{7}$ & $710^{13}$ & 0.01 & $710^{15}$ & Graphene \\
\hline 2D-0D hybrid² & $\mathrm{PbS}$ & $0.4-1.5$ & RT & $\begin{array}{l}2.6 \\
10^{-7} \\
\end{array}$ & $610^{5}$ & $510^{11}$ & $0.3-0.4$ & $1.210^{12}$ & $\mathrm{MoS}_{2}$ \\
\hline 2D-0D hybrid ${ }^{3}$ & $\mathrm{PbS}$ & 1.8 & RT & $10^{-8}$ & $1.410^{3}$ & $10^{12}$ & $\begin{array}{c}0.03- \\
0.2\end{array}$ & $\begin{array}{c}510^{12}-3 \\
10^{13}\end{array}$ & $\begin{array}{c}\mathrm{MoS}_{2} \text { and } \\
\mathrm{WS}_{2}\end{array}$ \\
\hline 2D-0D hybrid ${ }^{4}$ & $\mathrm{HgTe}$ & 2 & RT & $10^{-12}$ & $10^{5}$ & $\approx 10^{12}$ & $410^{-3}$ & $2.510^{14}$ & $\mathrm{TiO}_{2} / \mathrm{MoS}_{2}$ \\
\hline $2 \mathrm{D}-0 \mathrm{D}$ hybrid $^{5}$ & $\mathrm{HgTe}$ & 2.5 & RT & $10^{-7}$ & $10^{-7}$ & $N / R$ & $10^{-2}$ & $N / R$ & $\begin{array}{c}\text { Gate } \\
\text { tunable }\end{array}$ \\
\hline $\begin{array}{c}\text { Phototransisto } \\
r^{6} \\
\end{array}$ & $\mathrm{HgTe}$ & 2 & RT & $10^{-7}$ & 0.4 & $210^{10}$ & $10^{-5}$ & $210^{15}$ & $\begin{array}{c}\text { Spray } \\
\text { coating }\end{array}$ \\
\hline $\begin{array}{c}\text { Phototransisto } \\
r^{7} \\
\end{array}$ & $\mathrm{HgTe}$ & 2.5 & 220 & $10^{-8}$ & $10^{-5}$ & $N / R$ & $210^{-5}$ & $N / R$ & $\mathrm{LaF}_{3}$ gate \\
\hline $\begin{array}{c}\text { Phototransisto } \\
\mathrm{r}^{8}\end{array}$ & $\mathrm{HgTe}$ & 3.5 & 230 & $10^{-8}$ & $<0.1$ & $3.510^{10}$ & $N / R$ & $N / R$ & $\begin{array}{c}\mathrm{As}_{2} \mathrm{~S}_{3} \\
\text { surfac } \\
\text { chemistry }\end{array}$ \\
\hline Diode $^{9}$ & $\mathrm{HgTe}$ & $2.5 / 4$ & 100 & $10^{-6}$ & $\mathrm{~N} / \mathrm{R}$ & $310^{10}$ & $<10^{-6}$ & $310^{16}$ & Dual band \\
\hline Diode $^{10}$ & $\mathrm{HgTe}$ & 3 & RT & $\begin{array}{c}<10^{-} \\
8\end{array}$ & 0.02 & $310^{9}$ & $3.710^{-7}$ & $8.110^{15}$ & Ink \\
\hline Diode $^{11}$ & $\mathrm{HgTe}$ & 2.2 & RT & $N / R$ & 0.5 & $7.510^{10}$ & $1.210^{-8}$ & $6.210^{18}$ & Flexible \\
\hline
\end{tabular}




\begin{tabular}{cccccccccc}
\hline Diode $^{12}$ & $\mathrm{HgTe}$ & $4-5$ & 230 & $\begin{array}{c}<10^{-} \\
6\end{array}$ & 0.4 & $10^{9}$ & $0.310^{-6}$ & $3.310^{15}$ & MWIR \\
\hline $\begin{array}{c}\text { Photoconduct } \\
\text { or }^{13}\end{array}$ & $\mathrm{HgTe}$ & 2.3 & $\mathrm{RT}$ & $\mathrm{N} / \mathrm{R}$ & 0.9 & $810^{9}$ & $0.210^{-3}$ & $410^{13}$ & Flexible \\
\hline $\begin{array}{c}\text { Photoconduct } \\
\text { or }{ }^{14}\end{array}$ & $\mathrm{HgTe}$ & 4 & 80 & $10^{-8}$ & 0.15 & $510^{10}$ & $10^{-6}$ & $510^{16}$ & $\begin{array}{c}\text { High } \\
\text { mobility }\end{array}$ \\
\hline $\begin{array}{c}\text { Photoconduct } \\
\text { or }\end{array}$ & $\mathrm{PbS}$ & 1.5 & 250 & $\mathrm{~N} / \mathrm{R}$ & $210^{-1}$ & $210^{9}$ & $\mathrm{~N} / \mathrm{R}$ & $\mathrm{N} / \mathrm{R}$ & $\begin{array}{c}\text { Plasmonic } \\
\text { resonator }\end{array}$ \\
\hline $\begin{array}{c}\text { This work } \\
\text { 2D- }\end{array}$ & $\mathrm{HgTe}$ & 2.5 & 220 & $10^{-6}$ & $6.510^{-3}$ & $10^{9}$ & $<10^{-5}$ & $10^{14}$ & \\
$\begin{array}{c}\text { OD/phototransi } \\
\text { stor/diode }\end{array}$ & $\mathrm{HgTe}$ & & & & & & & \\
\hline \hline
\end{tabular}




\section{References}

(1) Konstantatos, G.; Badioli, M.; Gaudreau, L.; Osmond, J.; Bernechea, M.; Arquer, F. P. G. de; Gatti, F.; Koppens, F. H. L. Hybrid Graphene-Quantum Dot Phototransistors with Ultrahigh Gain. Nat. Nanotechnol. 2012, 7, 363-368.

(2) Kufer, D.; Nikitskiy, I.; Lasanta, T.; Navickaite, G.; Koppens, F. H. L.; Konstantatos, G. Hybrid 2D-0D MoS ${ }_{2}-\mathrm{PbS}$ Quantum Dot Photodetectors. Adv. Mater. 2015, 27, 176-180.

(3) Özdemir, O.; Ramiro, I.; Gupta, S.; Konstantatos, G. High Sensitivity Hybrid PbS CQD-TMDC Photodetectors up to 2 Mm. ACS Photonics 2019, 6, 2381-2386.

(4) Huo, N.; Gupta, S.; Konstantatos, G. $\mathrm{MoS}_{2}-\mathrm{HgTe}$ Quantum Dot Hybrid Photodetectors beyond 2 um. Adv. Mater. 2017, 29, 1606576.

(5) Tang, X.; Lai, K. W. C. Graphene/HgTe Quantum-Dot Photodetectors with Gate-Tunable Infrared Response. ACS Appl. Nano Mater. 2019, 2, 6701-6706.

(6) Chen, M.; Lu, H.; Abdelazim, N. M.; Zhu, Y.; Wang, Z.; Ren, W.; Kershaw, S. V.; Rogach, A. L.; Zhao, N. Mercury Telluride Quantum Dot Based Phototransistor Enabling High-Sensitivity Room-Temperature Photodetection at 2000 nm. ACS Nano 2017, 11, 5614-5622.

(7) Gréboval, C.; Noumbe, U.; Goubet, N.; Livache, C.; Ramade, J.; Qu, J.; Chu, A.; Martinez, B.; Prado, Y.; Ithurria, S.; Ouerghi, A.; Aubin, H.; Dayen, J.-F.; Lhuillier, E. Field-Effect Transistor and Photo-Transistor of Narrow-Band-Gap Nanocrystal Arrays Using lonic Glasses. Nano Lett. 2019, 19, 3981-3986.

(8) Lhuillier, E.; Keuleyan, S.; Zolotavin, P.; Guyot-Sionnest, P. Mid-Infrared HgTe/As $\mathrm{S}_{3}$ Field Effect Transistors and Photodetectors. Adv. Mater. 2013, 25, 137-141.

(9) Tang, X.; Ackerman, M. M.; Chen, M.; Guyot-Sionnest, P. Dual-Band Infrared Imaging Using Stacked Colloidal Quantum Dot Photodiodes. Nat. Photonics 2019 2019, 13, 277-282.

(10) Martinez, B.; Ramade, J.; Livache, C.; Goubet, N.; Chu, A.; Gréboval, C.; Qu, J.; Watkins, W. L.; Becerra, L.; Dandeu, E.; Fave, J. L.; Méthivier, C.; Lacaze, E.; Lhuillier, E. HgTe Nanocrystal Inks for Extended Short-Wave Infrared Detection. Adv. Opt. Mater. 2019, 1900348.

(11) Tang, X.; Ackerman, M. M.; Shen, G.; Guyot-Sionnest, P. Towards Infrared Electronic Eyes: Flexible Colloidal Quantum Dot Photovoltaic Detectors Enhanced by Resonant Cavity. Small 2019, 1804920, 1804920.

(12) Ackerman, M. M.; Tang, X.; Guyot-Sionnest, P. Fast and Sensitive Colloidal Quantum Dot Mid-Wave Infrared Photodetectors. ACS Nano 2018, 12, 7264-7271.

(13) Cryer, M. E.; Halpert, J. E. $300 \mathrm{~nm}$ Spectral Resolution in the Mid-Infrared with Robust, High Responsivity Flexible Colloidal Quantum Dot Devices at Room Temperature. ACS Photonics 2018, 5, 3009-3015.

(14) Chen, M.; Lan, X.; Tang, X.; Wang, Y.; Hudson, M. H.; Talapin, D. V.; Guyot-Sionnest, P. High Carrier Mobility in HgTe Quantum Dot Solids Improves Mid-IR Photodetectors. ACS Photonics 2019, 11, 48.

(15) Chu, A.; Gréboval, C.; Goubet, N.; Martinez, B.; Livache, C.; Qu, J.; Rastogi, P.; Bresciani, F. A.; Prado, Y.; Suffit, S.; Ithurria, S.; Vincent, G.; Lhuillier, E. Near Unity Absorption in Nanocrystal Based Short Wave Infrared Photodetectors Using Guided Mode Resonators. ACS Photonics 2019, 6, 2553-2561. 